\title{
Design Study of a Heavily Loaded Ice Class Propeller Using an Advance Panel Method
}

\author{
Pengfei Liu, ${ }^{1}$ Mohammed Fakhrul Islam, ${ }^{2}$ J. Michael Doucet, ${ }^{2}$ Andrew Prior, ${ }^{3}$ and Guojun Huang ${ }^{4}$
}

\begin{abstract}
A design and optimization procedure developed and used for a propeller installed on a twin-semitunnel-hull ship navigating in very shallow and icy water under heavy load conditions is presented. The base propeller for this vessel was first determined using classic design routines under open-water condition with existing model test data. In the optimization process, a panel method code (PROPELLA) was used to vary the pitch values and distributions and take into account the inflow wake distribution, tunnel gap, and cavitation effects. The optimized propeller was able to improve a ship speed of 0.02 knots higher than the desired speed and 0.06 knots higher than the classic B-series propeller. The analysis of the effect of inflow wake, hull tunnel, cavitation, and blade rake angle on propulsive performance is the focus of this paper.
\end{abstract}

Keywords: design (general); loads; ice; propellers

\section{Introduction}

WITH the development of computational technology, numerical expertise, and increasing demand of propellers working under extreme conditions, conventional design method alone has long been inadequate for designing propellers to work in extreme conditions. Computational hydrodynamic methods have a great advantage of reducing the cost of manufacturing model propellers and facility time and providing some performance results that could be very difficult to obtain in model tests. There are a huge amount of publications on lifting surface and panel method codes to evaluate hydrodynamic performance of a marine propeller, for example, the first application of panel method for marine propellers by Hess and Valarezo (1985) and then Kerwin and Lee (1978), who presented a hydrodynamic evaluation code using a lifting surface method. Few of these lifting surface theories or panel methods codes were applied and presented for a detailed design and optimization process, or in other words, few marine propeller design cases that fully utilized numerical code, especially for behind-ship propeller cavitation, were documented in literature. A few of these examples include a work for a high-speed patrol boat (Jessup \& Wang 1997), a scientific fishing ship propeller design using the panel method code (Hotaling et al. 2001), and a more recent podded propeller that was designed using an in-house panel method code (Bertaglia et al. 2004). This work is intended to develop and use such a procedure to design and optimize a propeller and to shed some light as a guideline on marine propeller design and optimization using an advanced hydrodynamic code.

\section{Procedure and method}

This section describes the design and optimization procedure and method. It is divided into the following subsections:

\footnotetext{
${ }^{1}$ Institute for Ocean Technology, National Research Council Canada, St. John's, NL, Canada.

${ }^{2}$ Oceanic Consulting Corporation, St. John's, NL, Canada.

${ }^{3}$ Fleetway Inc., Ottawa, Ontario, Canada.

${ }^{4}$ Department of Engineering Science, Institute of Mechanics, Chinese Academy of Sciences, Beijing, China.

Manuscript received at SNAME headquarters July 2008.
}

- Given conditions that are obtained from a self propulsion report (Baranowski 2005), including ship data with constraints, resistance, and power prediction data for minimum required propulsion efficiency, sea trial propulsion data for minimum thrust requirement, and maximum allowable torque requirement

- Base propeller geometry determination in terms of pitch and expanded area ratio that uses a classic $\mathrm{Bp}-\delta$ design method with a Wageningen B4 type propeller of several expanded area ratios in terms of minimum required area based on a primary cavitation check

- New base propeller determination that contains the method of determining the new base propeller, which is mainly a combination of the classic method with analysis

- Optimization of the new base propeller that includes a brief introduction of the panel method and optimization in terms of the variation of pitch values and distribution under the full-scale cavitation number, with the hull effect and inflow wake that is surveyed and extrapolated for full scale. During optimization, the in-house panel method code PROPELLA, as a principal design tool, including both pre- and postprocessors were used.

\subsection{Given conditions and input data preparation}

In this subsection, given conditions from the self-propulsion report (Baranowski 2005) are listed, and some of these data were manipulated for the calculation and input for the code.

2.1.1. Ship data. Ship data are tabulated in Table 1.

Figures 1, 2, 3 and 4 show the hull form diagram of the dual-semitunnel shallow water ice class ship, side view of the model ship, and the propeller arrangement at the stern of the twin-propeller ship.

The diameter of the full-scale propeller is limited to 1.60 meters.

2.1.2. Self-propulsion propeller data. Table 2 shows the self-propulsion data.

Table 3 shows the self-propulsion results for the hull with the stock propellers. Table 4 presents the extrapolated thrust and torque coefficients for full-scale propeller.

$A$ classic $\mathrm{Bp}-\delta$ diagram method was used to roughly estimate the requirement of propulsive performance. Table 5 
Table 1 Ship data

\begin{tabular}{lccc}
\hline Draught $(\mathrm{m})$ & Water Depth $(\mathrm{m})$ & Length $L_{\mathrm{p} p}(\mathrm{~m})$ & Scale Factor \\
\hline 1.2200 & 3.2000 & 48.05 & 10.7900 \\
\hline Physical Properties & Full Scale & Tank \\
\hline Temperature $t(\mathrm{deg} \mathrm{C})$ & 15.0000 & 16.5000 \\
Mass density $\rho\left(\mathrm{kg} / \mathrm{m}^{3}\right)$ & 999.0000 & 998.8000 \\
Kinematic viscosity $v\left(110^{6} \mathrm{~m} / \mathrm{s}\right)$ & 1.1390 & 1.0950 \\
\hline
\end{tabular}
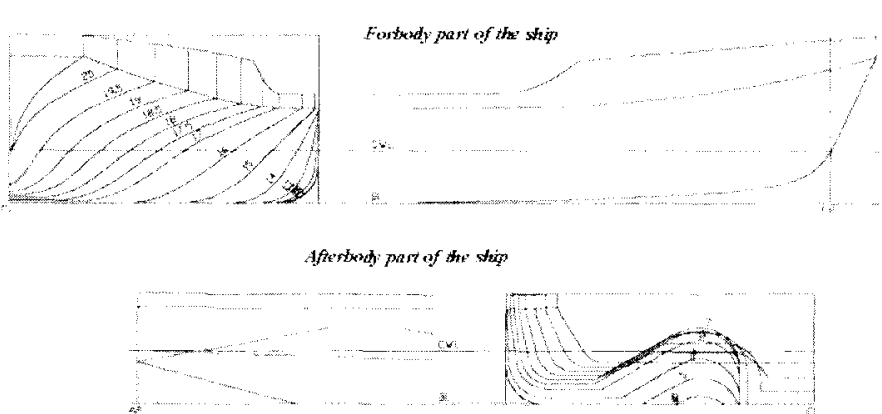

Fig. 1 Hull form diagram of the dual-semitunnel shallow water ice class ship

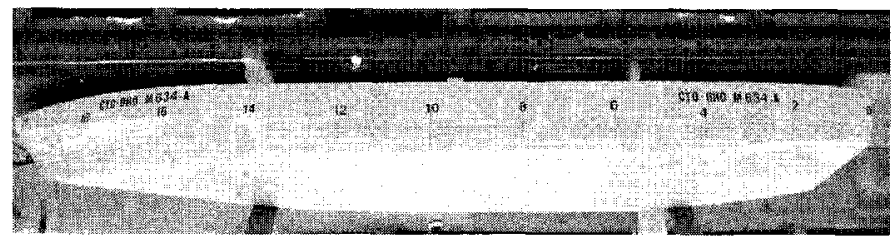

Fig. 2 Side view of the model ship

shows the estimated required thrusts and efficiencies at different ship speeds.

Table 5 reveals that to achieve a speed of $7.6 \mathrm{knots}$, the propeller should have an efficiency $(\eta)$ of 0.4229 or higher, a thrust coefficient $\left(K_{t}\right)$ of 0.2293 or higher, and a torque coefficient $\left(K_{\mathrm{q}}\right)$ of 0.0303 or lower.

2.1.3. Wake survey. Wake survey data were provided in the self-propulsion tests report. Figure 5 shows the axial wake in the propeller plane, view from the.

Figure 6 shows the circumferential distribution of the axial wake in the form of input for the code to simulate the behind-ship working condition, in terms of $1-V_{\mathrm{x}} / V_{\mathrm{m}}$. Note that the horizontal axis of the figure is the vertical axis in ship, that is, zero degree in the plot pointing north on the ship and the plot was viewed from bow.

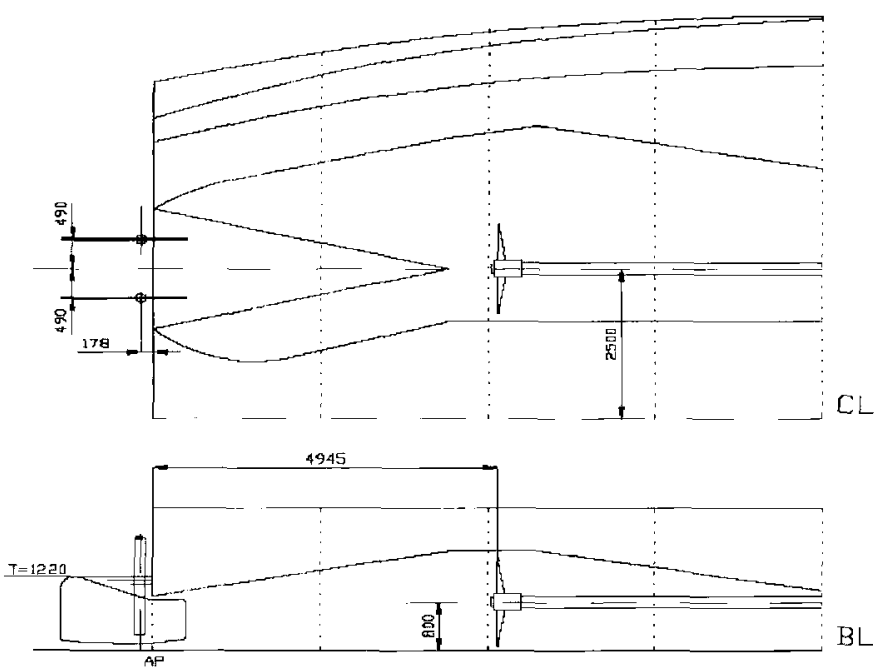

Fig. 3 Propeller arrangement at the stern of the twin-propeller ship
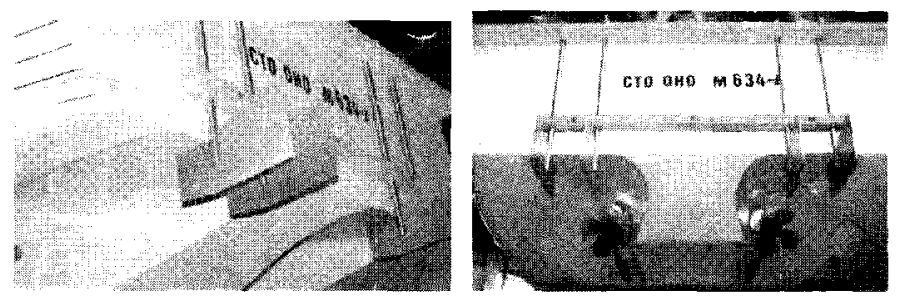

Fig. 4 Pictures of the stern side-rear view and rear view of the propulsion test arrangement

Table 2 Self-propulsion data

Propeller Model (s)

$\mathrm{P} 468$ \& P475

Number of blades $z$

Propeller diameter $D(\mathrm{~m})$

Pitch/diameter ratio at $0.7 R p / D$

Full-scale propeller revolution $N(\mathrm{rpm})$

1.6000

1.1100

449.50

Figure 7 shows the normalized radial components of the wake. Because of the hull shape at the propeller plane, the velocity profile is not perfectly symmetrical between the port and starboard side and is obviously asymmetric between near hull wall side (top) and bottom side.

Figure 8 shows the normalized tangential components of the wake in the propeller plane.

A strong asymmetry of the tangential velocity is shown between the midship side and the starboard side.

Nomenclature

$\mathrm{P}_{\mathrm{d}}=$ Delivered power

$\mathrm{V}_{\mathrm{s}}=$ Ship advance speed

$\mathrm{W}_{\mathrm{s}}=$ Wake fraction

$\mathrm{t}_{\mathrm{s}}=$ Thrust deduction factor

$J_{\mathrm{s}}=$ Ship advance coefficient

$\mathrm{V}_{\mathrm{a}}=$ Propeller shaft advance speed

$J_{p}=$ Propeller disk advance coefficient

$\mathrm{P}_{E S}=$ Effective shaft power (single propeller)

$\mathrm{P}_{\mathrm{DS}}=$ Delivered shaft power (single propeller)

$\rho=$ Fluid density $\mathrm{n}=$ Shaft rotation speed in $\mathrm{rps}$; subscripts $s$ and $m$ mean ship and model respectively

$\eta=$ Propeller efficiency; subscripts $\mathrm{s}$ and $\mathrm{m}$ mean ship and model respectively

$\mathrm{t}=$ Temperature

$\mathrm{R}=$ Propeller radius or ship hull resistance

$\mathrm{Kt}=$ Propeller thrust coefficient; subscripts $\mathrm{s}$ and $\mathrm{m}$ mean ship and model respectively

$\mathrm{Kq}=$ Propeller shaft torque coefficient; subscripts s and m mean ship and model respectively

Ts = Single propeller shaft trial thrust force

Qs = Single propeller shaft trial torque

$\mathrm{p} / \mathrm{D}=$ Propeller pitch diameter ratio

$\mathrm{z}=$ Number of propeller blades

$\mathrm{D}=$ Diameter of propeller

$\nu=$ Kinematic viscosity

$\mathbf{P}_{\mathrm{atm}}=$ Atmospheric pressure

$\mathrm{P}_{\text {vapor }}=$ Vapour pressure

$\mathrm{H}=$ Propeller shaft immersion depth 
Table 3 Power prediction from self-propulsion tests

\begin{tabular}{lrcccrl}
\hline \multicolumn{7}{c}{ Ship Condition: Trials } \\
\hline $\begin{array}{c}V_{\mathrm{S}} \\
(\mathrm{knots})\end{array}$ & $\begin{array}{c}P_{\mathrm{ES}} \\
(\mathrm{kW})\end{array}$ & $\begin{array}{c}2 \times P_{\mathrm{DS}} \\
(\mathrm{kW})\end{array}$ & $\begin{array}{c}n_{\mathrm{S}} \\
(\mathrm{rpm})\end{array}$ & $\begin{array}{c}T_{\mathrm{S}} \\
(\mathrm{kN})\end{array}$ & $\begin{array}{c}Q_{\mathrm{S}} \\
(\mathrm{kN} \cdot \mathrm{m})\end{array}$ & $F n_{\mathrm{h}}$ \\
\hline 6 & 66 & 258 & 171.3 & 20 & 7 & 0.551 \\
6.44 & 72 & 286 & 179.9 & 22 & 8 & 0.591 \\
7.07 & 127 & 478 & 213 & 32 & 11 & 0.649 \\
7.53 & 197 & 1561 & 316 & 78 & 24 & 0.691 \\
8.05 & 328 & 4492 & 449.3 & 161 & 48 & 0.738 \\
8.61 & 682 & 5042 & 467.2 & 176 & 52 & 0.79 \\
9.04 & 1001 & 5055 & 467.2 & 176 & 52 & 0.829 \\
10.02 & 1299 & 5059 & 467.6 & 176 & 52 & 0.92 \\
\hline
\end{tabular}

Table 4 Propulsion performance from self-propulsion tests

\begin{tabular}{lccccc}
\hline$V_{\mathrm{s}}$ (knots) & $J_{\mathrm{s}}$ Ship & $K_{\mathrm{ts}}$ & $K_{\mathrm{qs}}$ & $10 K_{\mathrm{qs}}$ & Efficiency \\
\hline 8.0500 & 0.3457 & 0.2193 & 0.0409 & 0.4087 & 0.2953 \\
8.6100 & 0.3556 & 0.2217 & 0.0409 & 0.4094 & 0.3065 \\
9.0400 & 0.3733 & 0.2217 & 0.0409 & 0.4094 & 0.3218 \\
8.0500 & 0.4134 & 0.2213 & 0.0409 & 0.4087 & 0.3563 \\
7.5300 & 0.4598 & 0.2148 & 0.0413 & 0.4131 & 0.3805 \\
7.0700 & 0.6404 & 0.1940 & 0.0417 & 0.4167 & 0.4744 \\
6.0000 & 0.6758 & 0.1874 & 0.0410 & 0.4100 & 0.4917 \\
6.4400 & 0.6907 & 0.1869 & 0.0425 & 0.4248 & 0.4837 \\
\hline
\end{tabular}

Thrust coefficient and torque coefficient for full-scale trials condition (sorted)

\subsection{Base propeller determination}

The number of blades and diameter of the propeller were fixed as a basic requirement for the base propeller determination. The classic $\mathrm{Bp}-\delta$ design method with a Wageningen B4 propeller of several expanded area ratios in terms of cavitation performance were used to make decisions about the particulars of the base propeller. Table 6 and Fig. 9 present the preliminary of particulars. In calculations, the diameter of propeller, shaft revolution speed and engine output power (shaft torque limit) are fixed.

2.2.1. Performance estimation. Based on the given fixed number of blades and diameter, at constant rotational speed and delivered power, the maximum reachable speed for a $\mathrm{B} 4-55, \mathrm{~B} 4-70$, and B4-85 propeller is around 7.57, 7.56, and $7.53 \mathrm{knots}$, respectively. The target is to achieve 7.6 knots or more while satisfying all the given operating conditions; so a new propeller must be designed and optimized to exceed the performance of these B-series propellers.

The expanded area ratios are normally determined by the cavitation allowance. Using the classic Burrill's method, the required blade area based on cavitation for the ice class propeller is determined (intersection of the two lines) and shown in Fig. 10.

With the target speed of 7.6 knots, the expanded area ratio (EAR) is $\mathrm{EAR}=0.7919$ and $P / D=0.83$. In this case, the equivalent propeller open-water advance coefficient is $J=$ 0.33 based on the estimated wake fraction factor from the self-propulsion tests. Cavitation number based on the formula in the current version of the code is then:

$$
\begin{aligned}
& \frac{P_{\mathrm{atm}}+\rho g(H-R)-P_{\text {vapor }}}{0.5 \rho n^{2} D^{2}} \\
& =\frac{101,300+1,000 \times 9.8 \times(1.22-0.8)-1,730}{0.5 \times 1,000 \times(449.5 / 60)^{2} 1.6^{2}}=1.4433
\end{aligned}
$$

and cavitation number based on classic references/chart calculation:

$$
\begin{aligned}
& \frac{P_{\mathrm{atm}}+\rho g(H-R)-P_{\text {vapor }}}{0.5 \rho V^{2}} \\
& =\frac{101,300+1,000 \times 9.8 \times(1.22-0.8)-1,730}{0.5 \times 1,000 \times\left[0.7 \pi(449.5 / 60)^{2} 1.6^{2}+V_{\mathrm{a}}^{2}\right]}=0.2985
\end{aligned}
$$

A semiempirical cavitation model was developed and implemented in the code. The detailed formulation and implementation were presented by Liu et al. (2001). In this work, the code was used only to predict the total percentage of cavity area on the blade surfaces. Cavitation is deemed not severe if the predicted total cavity area is less than $10 \%$, though the code can be used to optimize both the camber values and its distribution at each blade section and pitch distribution along the span. As there is no low noise requirement, cavitation evaluation in this work was performed only to avoid degradation of thrust and efficiency caused by to cavitation.

2.2.2. Strength validation for the base propeller. With the maximum thickness at $r / R=0.0$ and 1.0 of $t_{-\max }=$ $137.8 \mathrm{~mm}=0.0861 \mathrm{D}$ and $t_{-\max }=7.88 \mathrm{~mm}=0.0049 \mathrm{D}$, respectively, chord length at $0.2 R=0.512 \mathrm{~m}$, rake angle $=12 \mathrm{deg}$, number of blades $=4$, diameter of the propeller $=1.6 \mathrm{~m}$, shaft speed $=449.5 \mathrm{rpm}$, delivered power $=1175 \mathrm{HP}$, and IA Class for propeller thickness correction (FSICR 2005), the blade thickness distribution is given in Table 7 .

Table 5 Desired propulsive performance at different speeds

Propeller diameter $(\mathrm{m})$

Revolution speed (rpm)

Fluid density (tonne/ $\mathrm{m}^{3}$ )

Delivered power for each propeller $(\mathrm{kW})$

Effective power for each propeller $(\mathrm{kW})$

Ship speed (knots)

Ship speed $(\mathrm{m} / \mathrm{s})$

Propeller advance speed

Ship advance coefficient, $J_{\mathrm{s}}$

Wake fraction, $W_{\mathrm{s}}$

Thrust deduction fraction, $t$

Propeller advance coefficient, $J_{\mathrm{p}}$

Required resistance, $R=P_{\mathrm{e}} / V_{s}(\mathrm{kN})$

Required thrust for each propeller,

$T(\mathrm{kN}), P_{\mathrm{e}}=T^{*} V_{\mathrm{a}}$

Required $K_{\mathrm{t}}$ for each propeller

Required torque for each propeller,

$Q$ in $\mathrm{kN} \cdot \mathrm{m}, P_{\mathrm{d}}=2^{*} P_{\mathrm{I}}^{*} n^{*} Q$

Required $K_{\mathrm{q}}$ for each propeller

Required propeller efficiency, $\eta$
1.60

449.50

1.0250

859.00

102.00

7.60

3.91

4.20

0.3262

0.0747

0.6982

0.3506

52.17

86.4449

0.2293

18.24

0.0303

0.4229
100.00

7.5300

3.8742

4.0292

0.3232

0.0400

0.6740

0.3361

51.62

79.1775

0.2100

18.24

0.0303

0.3714

112.50
7.8000
4.0131
4.7286
0.3348
0.1783
0.7409
0.3945
56.07
108.18

0.2869

18.24

0.0303

0.5955

101.00
7.5600
3.8896
4.1074
0.3245
0.0560
0.6865
0.3427
51.93
82.84

0.2197

18.24

0.0303

0.3961

\subsection{0 \\ 7.5800 \\ 3.8999 \\ 4.1543 \\ 0.3254 \\ 0.0652 \\ 0.6925 \\ 0.3466 \\ 52.05}

84.64

0.2245

18.24

0.0303

0.4094
102.50

7.6200

3.9205

4.2509

0.3271

0.0843

0.7037

0.3546

52.29

88.24

0.2340

18.24

0.0303 0.4366 


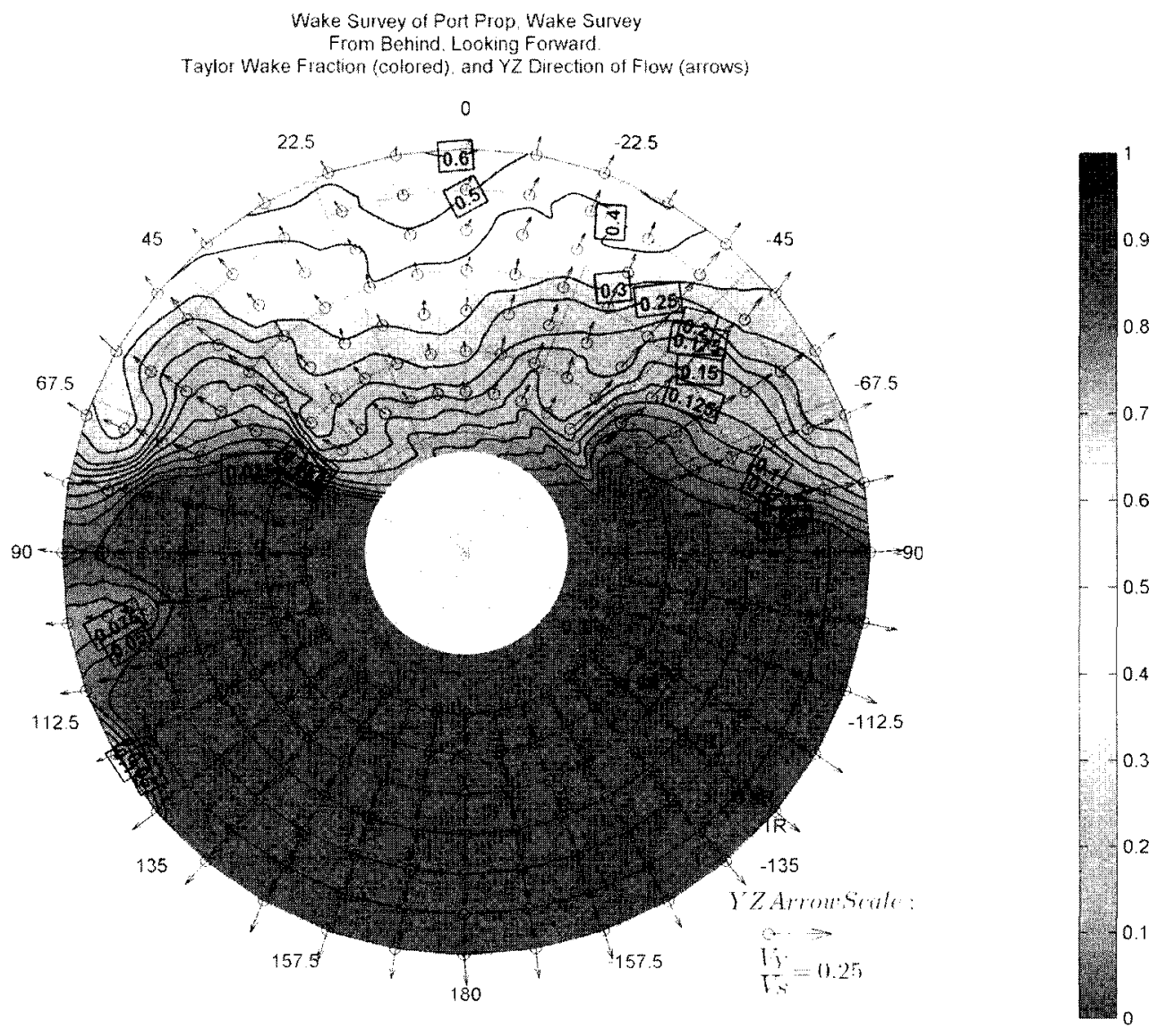

Degrees vs Prop Radius

Fig. 5 Axial wake distributions in the propeller plane

The maximum thickness at $1.0 R, 0.6 R$, and $0.25 R$ was based on the propeller made of $C 464$ naval brass/naval bronze with an ultimate tensile strength of $75 \mathrm{kpsi}$ (approximately $52 \mathrm{kp} / \mathrm{mm}^{2}$ ). As the propeller tip operates in a near open-water condition in that the blade tip is not going to collide with large ice block and with a substantial reduced pitch at the tip (about $65 \%$ of the pitch at $0.7 R$ ), the blade maximum thickness at the tip was designed with a thickness less than that recommended by the ice class rules. Thinner blade tip sections would reduce cavitation as well.

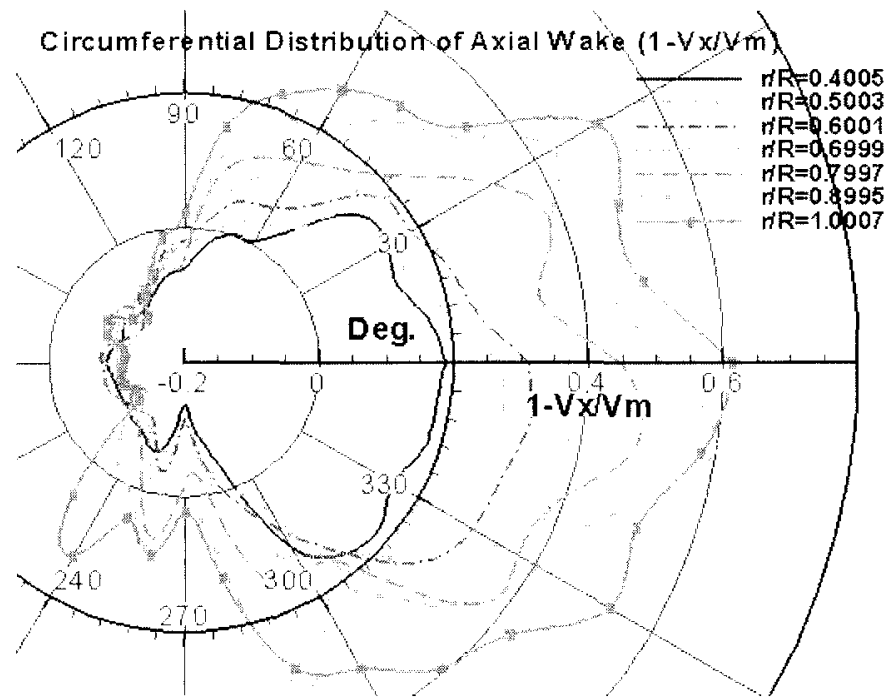

Fig. 6 Circumferential distribution of axial wake in the form for the code input

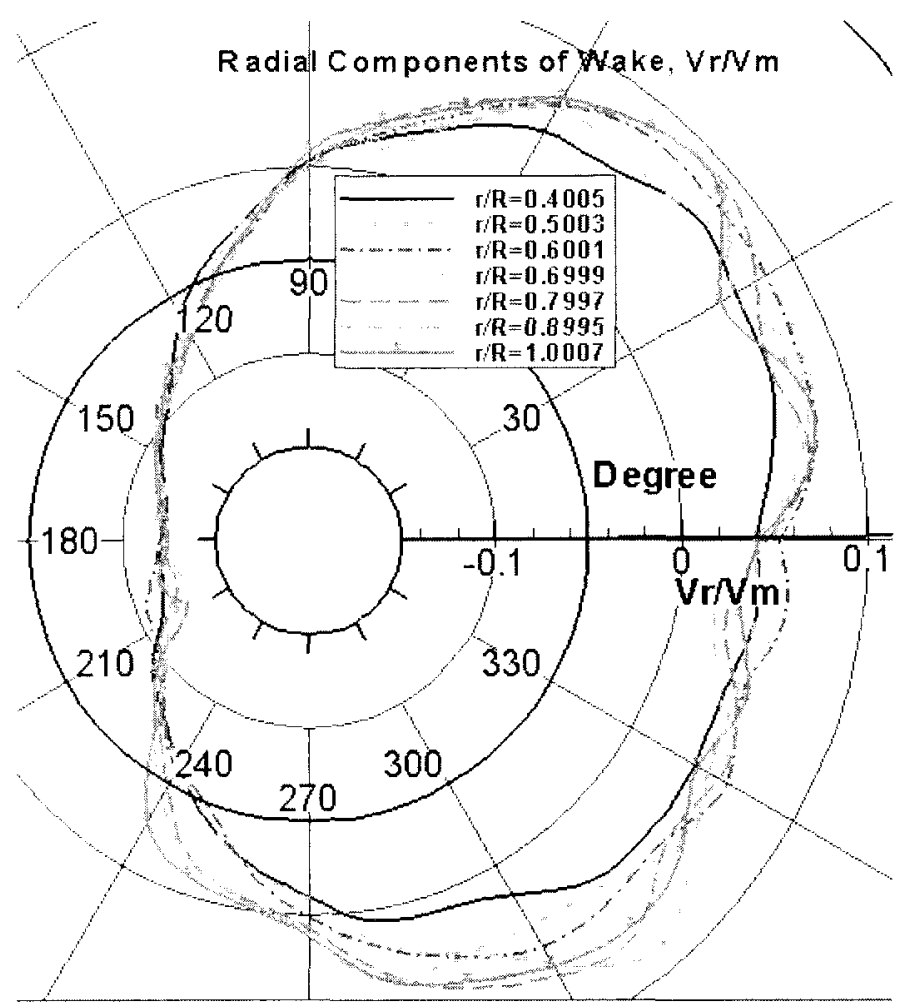

Fig. 7 Normalized radial components of the wake 


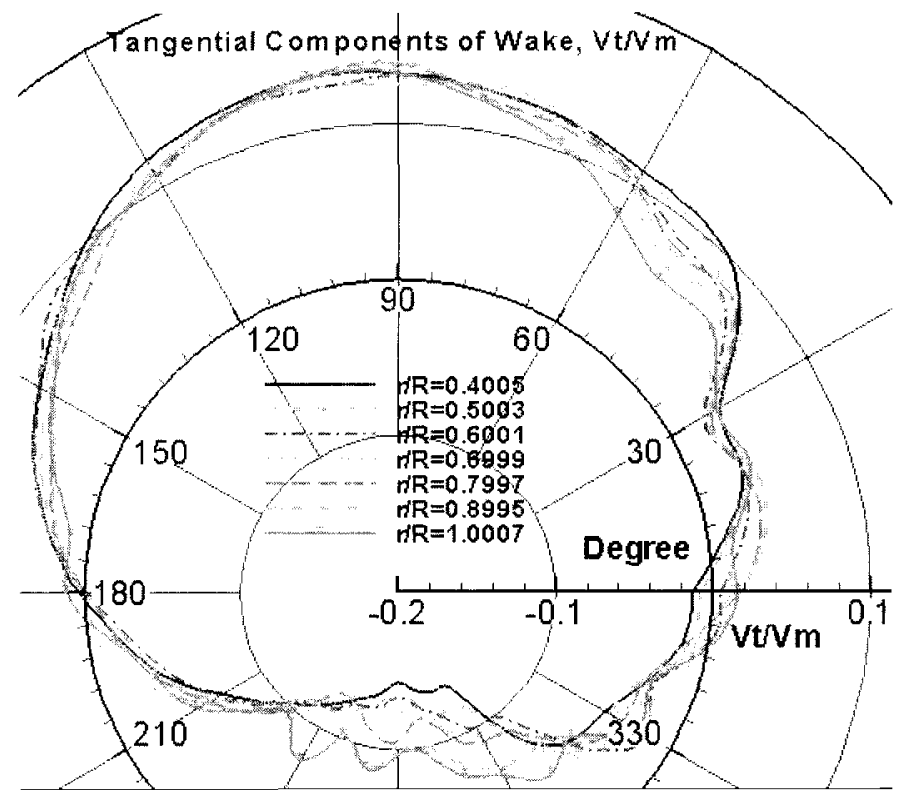

Fig. 8 Tangential components of the wake in the propeller plane

\subsection{New base propeller determination}

As mentioned in subsection 2.2.1, the base propeller cannot reach the required propulsive performance to get the ship at a speed of 7.6 knots. The base propeller has to be
Determination of speed and power

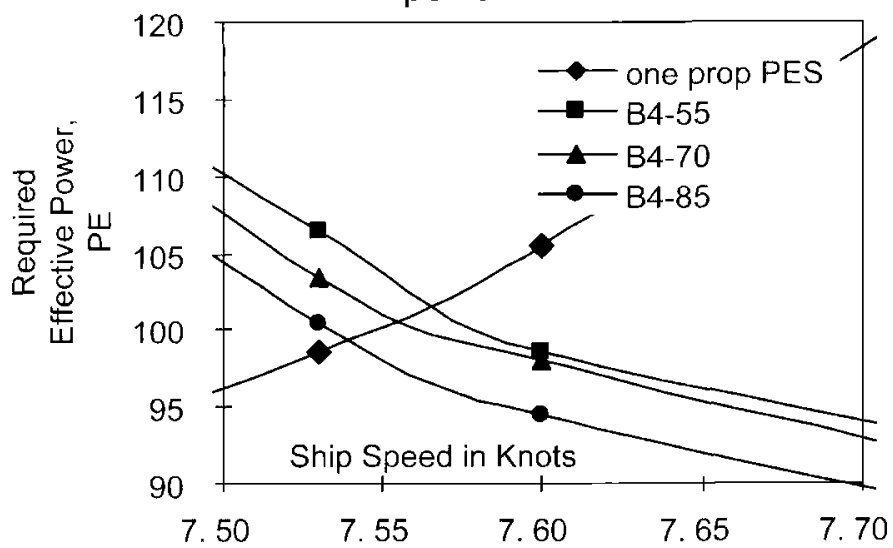

Fig. 9 Determination of speed and power for the base propeller

modified. A NACA 66 MOD sectional geometry with a mean line of $A=0.8$ was chosen. If this sectional type still cannot satisfy the propulsion performance, a more detailed modification on the individual section will be performed.

The planform shape of the new base propeller is designed based on the PP0000C0 propeller model, which is a base propeller for a podded propeller series (Liu 2006). With a consideration of the tunnel effect, which is similar to a

Table 6 Determination of the base propeller based on B-series

\begin{tabular}{|c|c|c|c|c|c|}
\hline \multirow[b]{2}{*}{$P_{\mathrm{d}}$} & \multicolumn{5}{|c|}{ Constant power and rpm for B4 to 55} \\
\hline & Delivered power (Emperor HP) & $1, \mathbf{1 6 7 . 3 5}$ & $1,167.35$ & $1,167.35$ & $1,167.35$ \\
\hline$V_{\mathrm{s}}^{\mathrm{a}}$ & Knot & 7.07 & 7.53 & 7.60 & 8.05 \\
\hline$W_{\mathrm{s}}$ & Wake fraction & 0.12 & -0.04 & -0.07 & -0.33 \\
\hline$t$ & Thrust deduction & 0.46 & 0.67 & 0.70 & 0.75 \\
\hline$J$ & Ship advance coefficient & 0.30 & 0.32 & 0.33 & 0.35 \\
\hline$V_{\mathrm{a}}$ & Knot & 6.23 & 7.83 & 8.16 & 10.71 \\
\hline$J_{\mathrm{p}}$ & Propeller disk advance coefficient & 0.27 & 0.34 & 0.35 & 0.46 \\
\hline Pitch ratio & From the $B p-\delta$ diagram & 0.77 & 0.79 & 0.81 & 0.82 \\
\hline eta_o & Propeller efficiency & 0.35 & 0.42 & 0.43 & 0.53 \\
\hline eta_h & Hull efficiency & 0.62 & 0.31 & 0.28 & 0.18 \\
\hline eta_r & Relative rotation efficiency & 0.88 & 0.94 & 0.94 & 0.95 \\
\hline Total efficiency & eta all & 0.19 & 0.12 & 0.11 & 0.09 \\
\hline$P_{\mathrm{e}}$ & Thrust power $=P_{\mathrm{d}}{ }^{*}$ eta_o $0^{*}$ eta_h*eta_r $(\mathrm{kW})$ & 164.45 & 106.42 & 98.48 & 80.19 \\
\hline & $P_{\mathrm{e}}=P_{\mathrm{d}}^{*}$ eta_o*eta_h*eta_r (English HP) & 223.74 & 144.78 & 133.99 & 109.10 \\
\hline Thrust force & $\mathrm{Kg}$ & $5,236.31$ & $2,695.07$ & $2,392.42$ & $1,485.47$ \\
\hline
\end{tabular}

Constant power and rpm for B4 to 70

\begin{tabular}{|c|c|c|c|c|c|}
\hline Pitch ratio & Look up the $\mathrm{Bp}-\delta$ diagram & 0.79 & 0.82 & 0.84 & 0.85 \\
\hline eta_o & Propeller efficiency & 0.34 & 0.41 & 0.43 & 0.51 \\
\hline eta_h & Hull efficiency & 0.62 & 0.31 & 0.28 & 0.18 \\
\hline eta $\mathbf{r}$ & Relative rotation efficiency & 0.94 & 0.94 & 0.94 & 0.94 \\
\hline Total efficiency & eta_all & 0.20 & 0.12 & 0.11 & 0.09 \\
\hline$P_{\mathrm{e}}$ & Thrust power $=P_{\mathrm{d}}{ }^{*}$ eta_o*eta_h*eta_r $(\mathrm{kW})$ & 169.27 & 103.43 & 97.94 & 75.92 \\
\hline & $P_{\mathrm{e}}=P_{\mathrm{d}}{ }^{*}$ eta_o*eta_h*eta_r $($ English HP) & 230.30 & 140.72 & 133.25 & 103.29 \\
\hline Thrust force & $\mathrm{kg}$ & $5,389.93$ & $2,619.50$ & $2,379.23$ & $1,406.32$ \\
\hline
\end{tabular}

Constant power and rpm for B4 to 85

\begin{tabular}{|c|c|c|c|c|c|}
\hline Pitch ratio & look up the $\mathrm{Bp}-\delta$ diagram & 0.74 & 0.83 & 0.84 & 0.85 \\
\hline eta_o & Propeller efficiency & 0.33 & 0.40 & 0.42 & 0.50 \\
\hline eta_h & Hull efficiency & 0.62 & 0.31 & 0.28 & 0.18 \\
\hline eta_r & Relative rotation efficiency & 0.94 & 0.94 & 0.94 & 0.94 \\
\hline Total efficiency & eta_all & 0.19 & 0.12 & 0.11 & 0.09 \\
\hline$P_{\mathrm{e}}$ & Thrust power $=P_{\mathrm{d}}{ }^{*}$ eta_o*eta_h*eta_r $(\mathrm{kW})$ & 164.30 & 100.41 & 94.52 & 74.43 \\
\hline & $P_{\varepsilon}=P_{\mathrm{d}}^{*}$ eta_o*eta_h*eta_r (English HP) & 223.53 & 136.61 & 128.60 & 101.26 \\
\hline Thrust force & $\mathrm{kg}$ & $5,231.40$ & $2,542.83$ & $2,296.24$ & $1,378.75$ \\
\hline
\end{tabular}




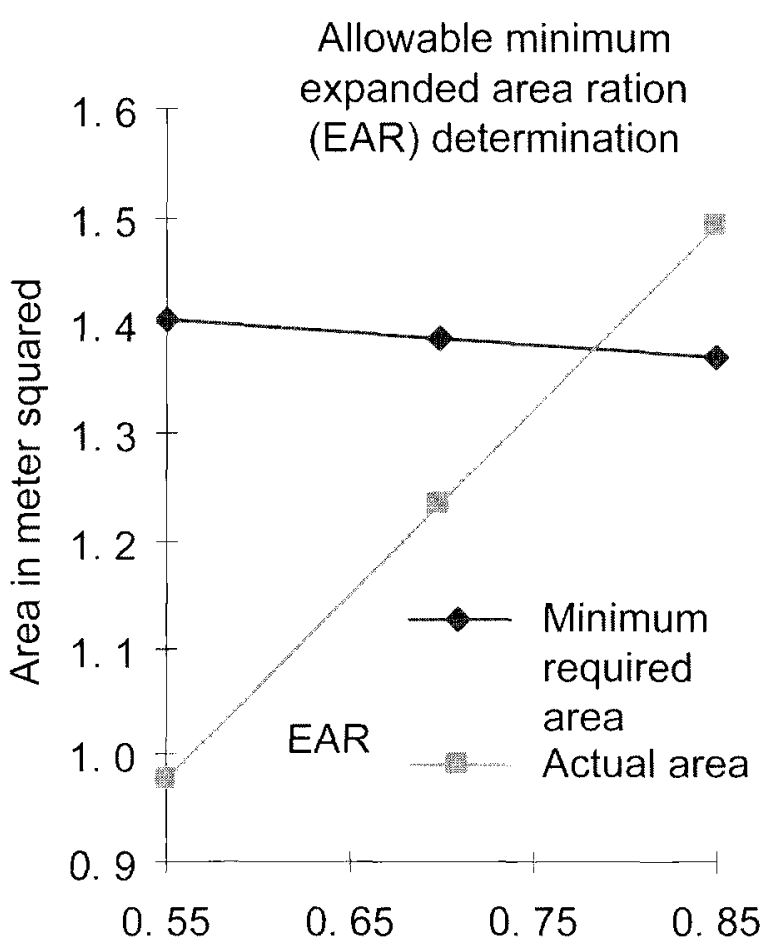

Fig. 10 Determination of minimum required area for heavily loaded propeller

Table 7 Modified thickness distribution for the base propeller

\begin{tabular}{ccc}
\hline$r / R$ & $t / D$ & $t / c$ \\
\hline 0.0000 & 0.1124 & \\
0.2000 & 0.0870 & \\
0.3000 & 0.0749 & 0.2018 \\
0.4000 & 0.0635 & 0.1533 \\
0.5000 & 0.0530 & 0.1179 \\
0.6000 & 0.0430 & 0.0912 \\
0.7000 & 0.0338 & 0.0715 \\
0.8000 & 0.0251 & 0.0564 \\
0.9000 & 0.0168 & 0.0455 \\
0.9500 & 0.0129 & 0.0454 \\
1.0000 & 0.0090 & 0.0552 \\
\hline
\end{tabular}

propeller with a nozzle, a much wider blade tip was taken. The nominal pitch at $0.7 R$ is 0.83 as shown in Table 8 for the planform information.

A rake of $12 \mathrm{deg}$ was chosen to improve the inflow of the propeller. The hub diameter ratio for this type of ice class propeller was taken as 0.26 with zero skew.

Table 8 Planform geometry details of the propeller

\begin{tabular}{ccccc}
\hline$r / R$ & $c / d$ & $p / d$ & $t / c$ & $f / c$ \\
\hline 0.3000 & 0.3712 & 0.8300 & 0.1553 & 0.0232 \\
0.4000 & 0.4145 & 0.8300 & 0.1180 & 0.0230 \\
0.5000 & 0.4498 & 0.8300 & 0.0916 & 0.0218 \\
0.6000 & 0.4721 & 0.8300 & 0.0696 & 0.0207 \\
0.7000 & 0.4733 & 0.8300 & 0.0542 & 0.0200 \\
0.8000 & 0.4452 & 0.8300 & 0.0421 & 0.0197 \\
0.9000 & 0.3700 & 0.8300 & 0.0332 & 0.0182 \\
0.9500 & 0.2842 & 0.8300 & 0.0323 & 0.0163 \\
1.0000 & 0.1638 & 0.8300 & 0.0316 & 0.0118 \\
\hline
\end{tabular}

Sectional geometry offsets for new ice class propeller based on $\mathrm{PP} 0000 \mathrm{CO}$ in the radial direction

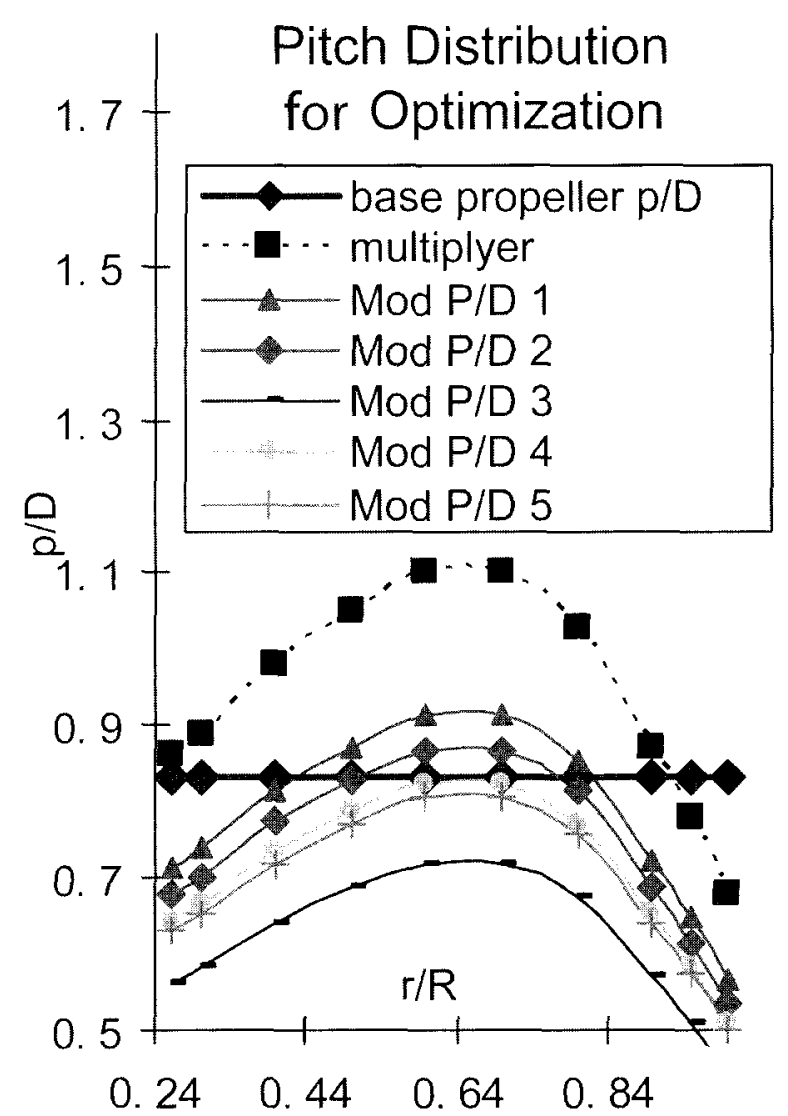

Fig. 11 Various pitch distributions used in the process of optimization

\subsection{Optimization of the new base propeller}

Propeller performance was estimated with the variation of pitch value and distributions. Figure 11 shows the various pitch values and distributions in the optimization.

A comprehensive software package, PROPELLA was extensively used for the optimization work (Liu 1996, Liu \& Bose 1998, Liu 2002). PROPELLA is a three-dimensional, unsteady panel method code for the evaluation of propeller thrust and torque (shaft and blade torque/bending moments) and for the design and optimization of a prototype propeller. This software package has the ability to model ducts and rudders and other arbitrary bodies in the vicinity of the propeller, with/without inflow wake. PROPELLA has been validated against published data for a range of propeller types, including B-series, a number of ice class propeller, and Kaplan as well as highly skewed models. PROPELLA enables the user to visualize the pressure distribution over the propeller blade and hub and to examine loads and sheet cavitation areas on a per-blade basis. This capability is useful in examining cyclic loading resulting from wake characteristics or flow blockages.

There are 24 runs to complete the computation for the propeller with $1.60 \mathrm{~m}$ diameter. These runs include the five runs of different pitching values and distributions at the design advance coefficient, $J=0.33$. Four additional runs to study the effects of rake angle on propulsive performance at design $J$ and optimized pitch distributions. Some additional runs were also performed to study the hull effect, cavitation effect, and inflow wake effect at all the pitch distributions.

\subsection{Summary of the optimized propeller}

Propulsive performance of the three different pitch values (two pitch values are not shown) is shown in Fig. 12. 
Nominal Pitch vs. Performance

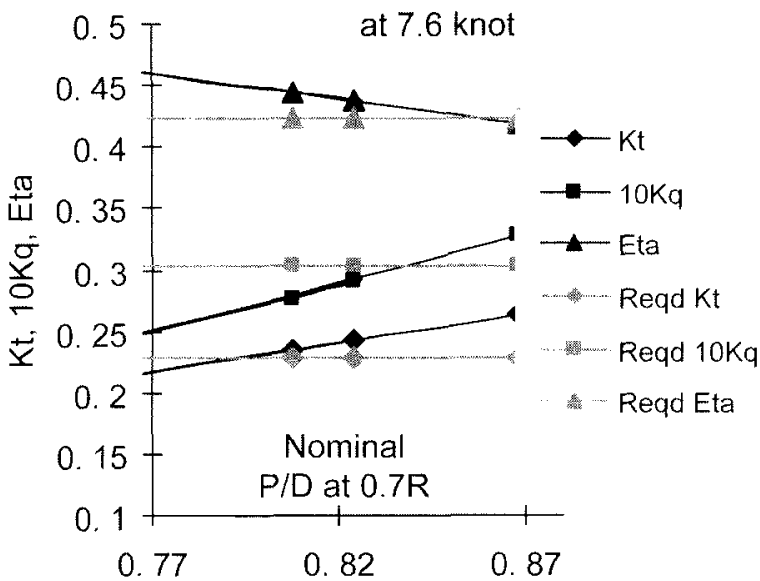

Fig. 12 Nominal pitches versus propulsive performance for $1.6 \mathrm{~m}$ diameter propeller

In the figure, the straight lines are required minimum thrust coefficient, $K_{\mathrm{t}}$ for $7.6 \mathrm{knots}$, maximum allowable torque coefficient, $10 K_{\mathrm{q}}$ (limited power consumption), and minimum required efficiency, $\eta$.

Pitch distribution 4 was selected primarily as it satisfies the required thrust and efficiency at $J=0.33$ (7.56 knots). Further simulations have been performed at higher advance coefficients (at higher propeller advance speed), which marginally satisfy required thrust and efficiency conditions. Finally, at $J=0.3546$ ( 7.62 knots), the thrust requirement is satisfied. The finalized particulars of the optimized propeller are summarized in Tables 9, 10, and 11, as general, planform profile, and sectional offset information, respectively.

Table 9 Optimized propeller geometry parameters

\begin{tabular}{ll}
\hline Propeller diameter, $D(\mathrm{~m})$ & 1.6 \\
Expand area ratio, EAR & 0.7919 \\
Number of blades & 4 \\
Propeller rotational speed (rpm) & 449.5 \\
Pitch distribution $(\mathrm{D})$ & \\
$r / R=0.26$ & 0.6442 \\
$r / R=0.7$ & 0.824 \\
$r / R=1.0$ & 0.5094 \\
Hub diameter ratio $(\mathrm{D})$ & 0.26 \\
Maximum thickness ratios & \\
$r / R=0.0$ & 0.1124 \\
$r / R=0.2$ & 0.0870 \\
$r / R=0.9$ & 0.0168 \\
$r / R=1.0$ & 0.009 \\
Equivalent flow conditions in classic propeller design & \\
Design advance speed (knots) & 7.62 \\
Wake fraction, $W_{\mathrm{s}}$ & 0.0843 \\
Thrust deduction, $t$ & 0.7037 \\
Design advance coefficient $J$ & 0.3546 \\
\hline
\end{tabular}

Table 10 Propeller planform profile details

\begin{tabular}{lcccc}
\hline$r / R$ & $c / D$ & $p / D$ & Skew & Rake \\
\hline 0.30 & 0.3712 & 0.6667 & 0.0000 & 0.2125 \\
0.40 & 0.4145 & 0.7341 & 0.0000 & 0.2125 \\
0.50 & 0.4498 & 0.7865 & 0.0000 & 0.2125 \\
0.60 & 0.4721 & 0.8240 & 0.0000 & 0.2125 \\
0.70 & 0.4733 & 0.8240 & 0.0000 & 0.2125 \\
0.80 & 0.4452 & 0.7720 & 0.0000 & 0.2125 \\
0.90 & 0.3700 & 0.6517 & 0.0000 & 0.2125 \\
0.95 & 0.3300 & 0.5843 & 0.0000 & 0.2125 \\
1.00 & 0.2842 & 0.5094 & 0.0000 & 0.2125 \\
\hline
\end{tabular}

Table 11 Propeller sectional offset profile detalls

\begin{tabular}{lcccc}
\hline$r / R$ & $t / c$ & $f / c$ & $t(\mathrm{~mm})$ & $f(\mathrm{~mm})$ \\
\hline 0.30 & 0.2018 & 0.0232 & 119.8631 & 13.76707 \\
0.40 & 0.1533 & 0.0230 & 101.6507 & 15.2735 \\
0.50 & 0.1179 & 0.0218 & 84.82861 & 15.70342 \\
0.60 & 0.0912 & 0.0207 & 68.85859 & 15.65106 \\
0.70 & 0.0715 & 0.0200 & 54.13741 & 15.16832 \\
0.80 & 0.0564 & 0.0197 & 40.17429 & 14.01133 \\
0.90 & 0.0455 & 0.0182 & 26.95007 & 10.75664 \\
0.95 & 0.0454 & 0.0163 & 23.98097 & 8.61168 \\
1.00 & 0.0552 & 0.0118 & 25.11066 & 5.34296 \\
\hline
\end{tabular}

Figure 13 shows the mesh view generated and panelized by PROPELLA for computational runs.

During computations, the hull gap effect, that is, nozzle effect, was taken into account by including the region of the hull around the propeller. Figures 14 and 15 are the rear and bottom view of the propeller-hull interaction mesh.

Figure 16 is the rear view of the propeller inside the semitunnel.

\section{Some hydrodynamic characteristics of the optimized propeller}

Figure 17 shows $K_{\mathrm{t}}$ and $K_{\mathrm{q}}$ fluctuations over one revolution (0 deg of key blade is pointing north, going in clockwise

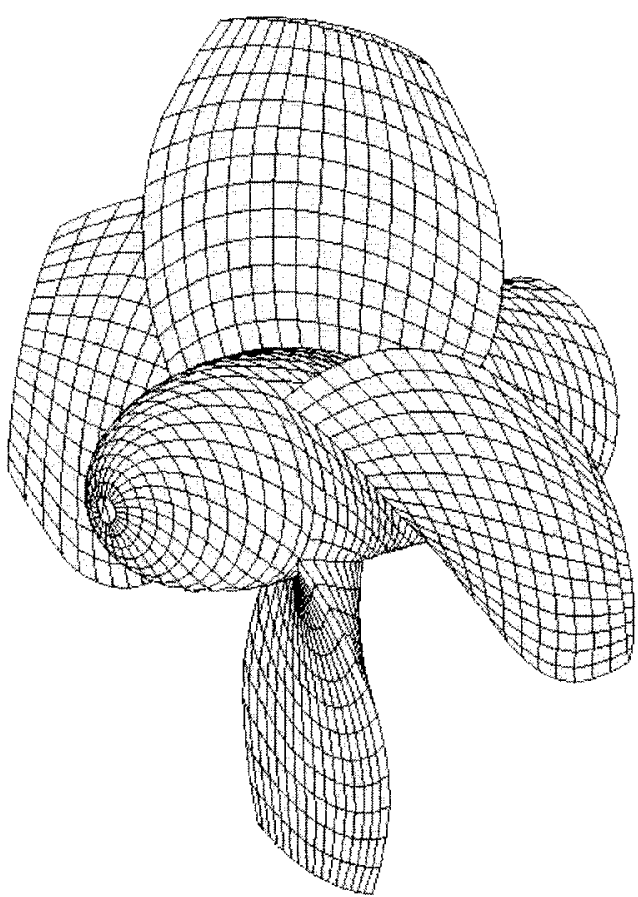

Fig. 13 Surface view of the optimized propeller, produced by the code PROPELLA

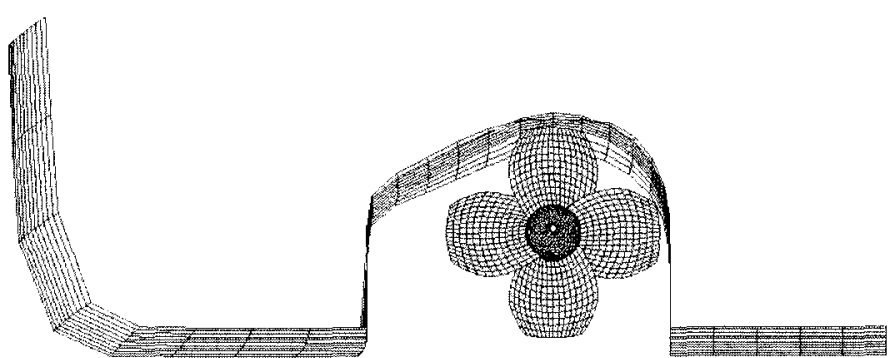

Fig. 14 Propeller-hull arrangements for computations viewing from stern to bow 


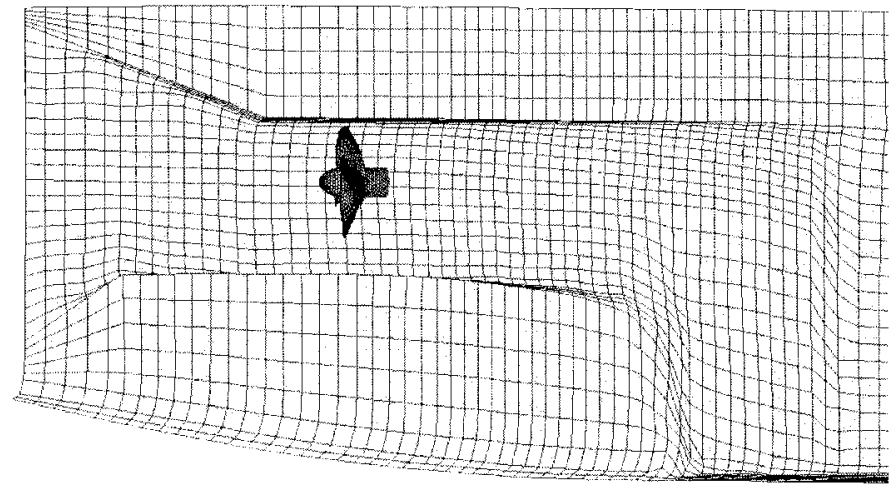

Fig. 15 Bottom view of the port propeller in the semitunnel under a rear part of the half hull

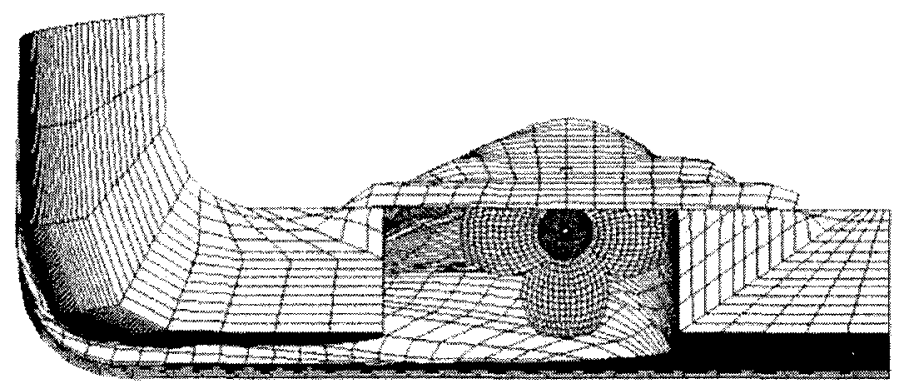

Fig. 16 Rear view of the port propeller in the semitunnel under a rear part of the half hull

direction), at an advance coefficient of $J=0.3546$ (speed of propeller shaft $V_{\mathrm{a}}=7.62 \mathrm{knots}$ ).

It can be seen that at $90 \mathrm{deg}$, when a blade is at horizontal position pointing at the shaft center of the other propeller, the shaft torque and thrust reached maximum, but the increase of torque and thrust with other positions is not enough to create a severe vibration.

Figure 18 shows the pressure coefficient before and after cavitation correction for blade section at $0.72 R$ at $0,90,180$, and 270 deg of key blade location.

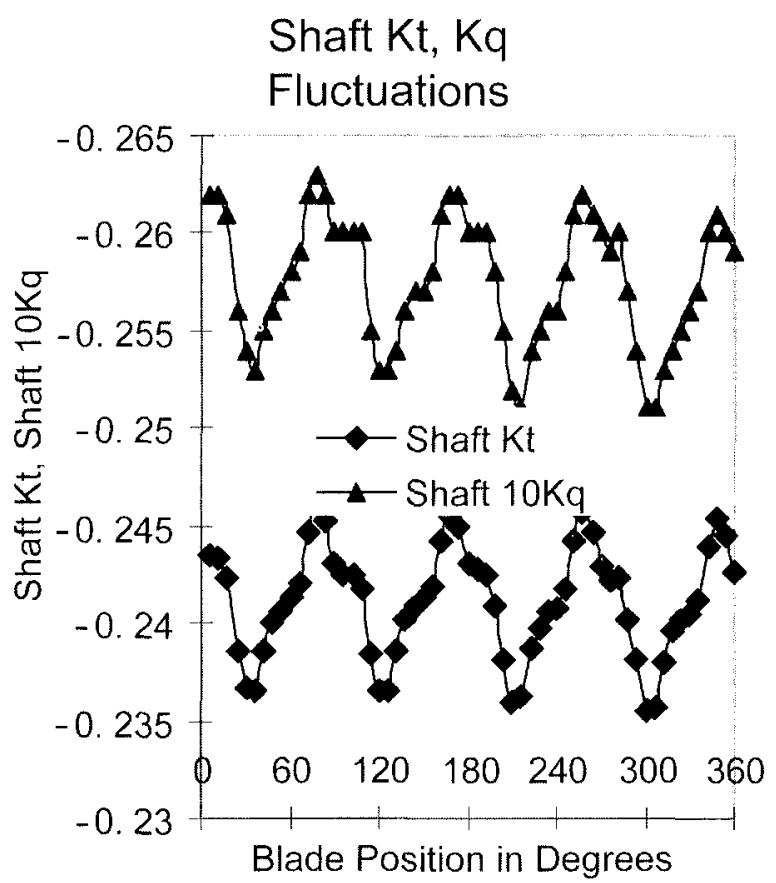

Fig. 17 Shaft thrust and torque coefficients fluctuations over one propeller rotation
When the key blade is at the midship position, it has the maximum negative pressure with a little cavitation at the lead edge (top left plot).

Figure 19 shows the history of the pressure coefficient distribution over one blade surface over one revolution.

It can be seen that pressure fluctuation is substantial because of the inflow wake under behind-ship working condition. A large pressure spike at the leading edge appears at the 90 deg location (the propeller blade upright pointing at the positive $z$-direction is at $0 \mathrm{deg}$ ). The tip of the pressure spike was chopped off because of the limitation of cavitation inception pressure defined in the cavitation simulation model (see Fig. $18 a$ and the curve in Fig. 19 as a result of the cavitation model developed in Liu et al. 2001).

\subsection{Effect of presence of inflow wake}

Figure 20 shows the performance comparison of the optimized propeller working in the wake of the tunnel hull (behind-ship condition) and working in the open water for various pitch distributions at $J=0.33$ and $n=7.5 \mathrm{rps}$.

It can be seen that with inflow wake taken into account the propeller gave a better propulsive performance in terms of efficiency, with both increased thrust and torque. The increased efficiency is attributed to the hull tunnel shape that is comparable with the situation between a nozzle propeller and an open propeller.

\subsection{Effect of presence of tunnel gap}

Figure 21 shows the comparison of the propeller with and without tunnel gap effect, with a variation of pitch distributions at $J=0.33$ and $n=7.5$ rps.

From the figure it is noted that the tunnel gap has a decrease in thrust and more drop in torque with a combined higher efficiency. This is similar to the nature of nozzle propellers.

\subsection{Comparison of the designed propeller and the stock propeller}

A comparison of propulsive performance between the designed and stock propellers is shown in Fig. 22.

In Fig. 22, numerical predictions were obtained for the propellers working under propeller-hull interaction, inflow wake, and cavitation correction. It can be seen that the best efficiency for the design propeller is at about $J=0.6$ and for the stock propeller at $J=0.9$. In this simulation, inflow nominal wake fraction for the speed of 7.6 knots was used for all the $J$ values. Cavitation correction was performed using the empirical cavitation model discussed previously.

\subsection{Some notes on design process}

- Variation of the pitch distribution was adjusted for two main design objectives: (1) to reduce cavitation area at the blade tip region (by reducing the pitch there) and to reduce the total cavity area of the blades by performing a number of trial runs for various pitch values and distribution functions to avoid the degradation of the thrust and efficiency caused by cavitation, and (2) at the same time to maintain the minimum thrust production requirement. More delicate optimization for propulsive performance can be made by modifying the sectional shape (camber and its distribution). The code also provides the environment for inflow wake adapted pitch distribution optimization though in the current work it was not performed.

- Both the rake and skew distribution were set constant. They are important factors for propulsion performance, 


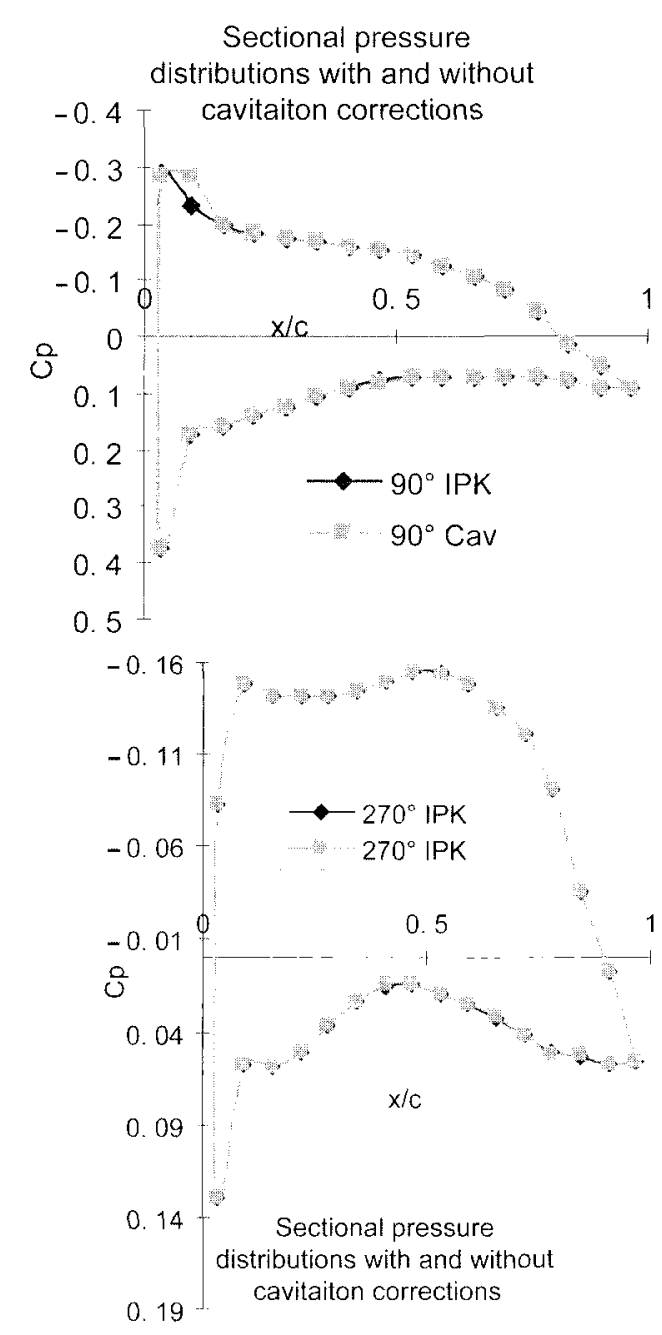

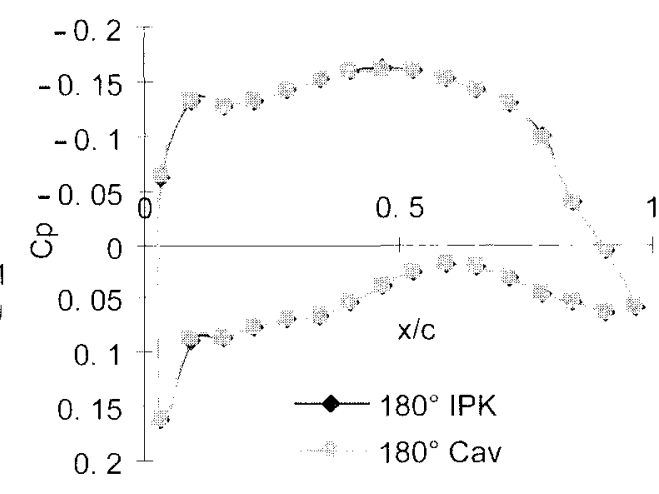

Sectional pressure

distributions with and without cavitaiton corrections

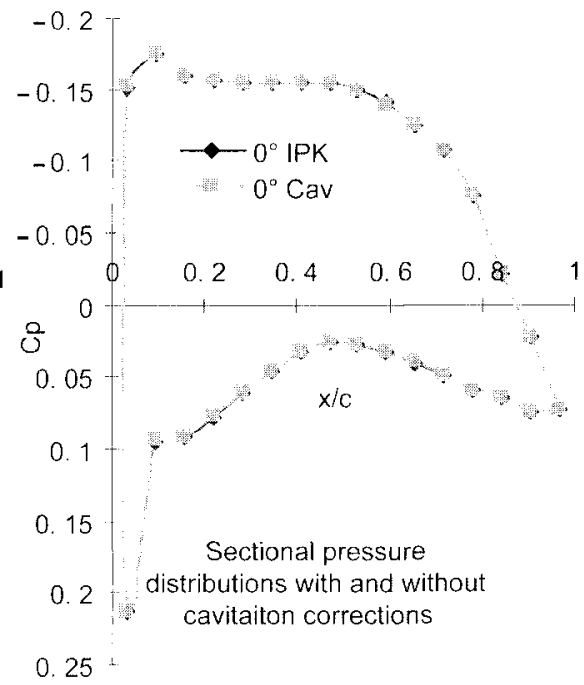

Fig. 18 Pressure coefficients before and after cavitation correction for blade section at $0.72 R$ at $0,90,180$, and 270 deg of key blade location

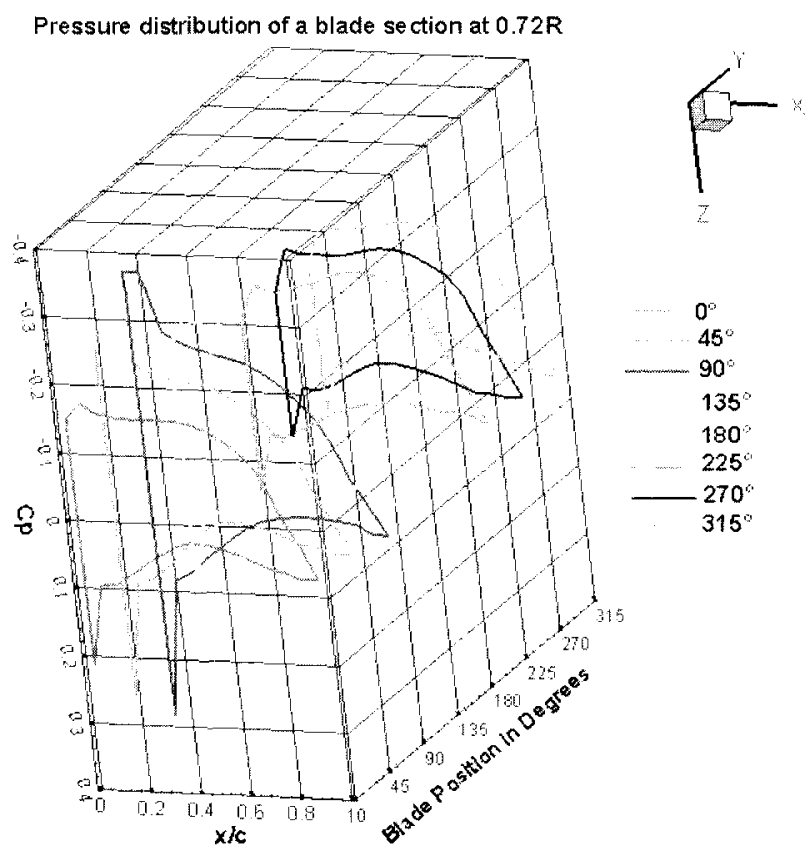

Fig. 19 Fluctuation of blade surface pressure distribution over one revolution along with the blade section at $0.72 \mathrm{R}$ especially for a poor inflow wake profile of the ship in this work. As changing pitch distribution is the most effective way to achieve the required thrust and efficiency and in this case the change of pitch distribution could meet and had met the design requirements, optimization of rake and skew was not performed.

- With respect to cavitation assessment, pitch distribution was the only variable in evaluation of cavitation. In cavitation assessment, cavitation inception was determined by a semiempirical model validated against a high-speed Italian propeller presented in detail by Liu et al. (2001). As mentioned previously, in addition to minimizing the total cavity area of all blades, variation of pitch distribution has to meet the minimum thrust production and efficiency requirements.

- The nominal wake shown in Figs. 5 to 6 was measured at the propeller disk plane in the tunnel shown in Figs. 14 to 16 (Baranowski 2005). This nominal wake was then included in all computational runs in the design and optimization process. The propeller-hull interaction was also simulated, and the interaction effect is substantial as if the propeller is in a nozzle, as shown in Fig. 21.

- For heavily loaded conditions, separation and stall often occur to degrade the thrust and efficiency. For this particular application case, Reynolds number is higher than 20 million. At this very large Reynolds number, separation and stall would occur at a large angle of 


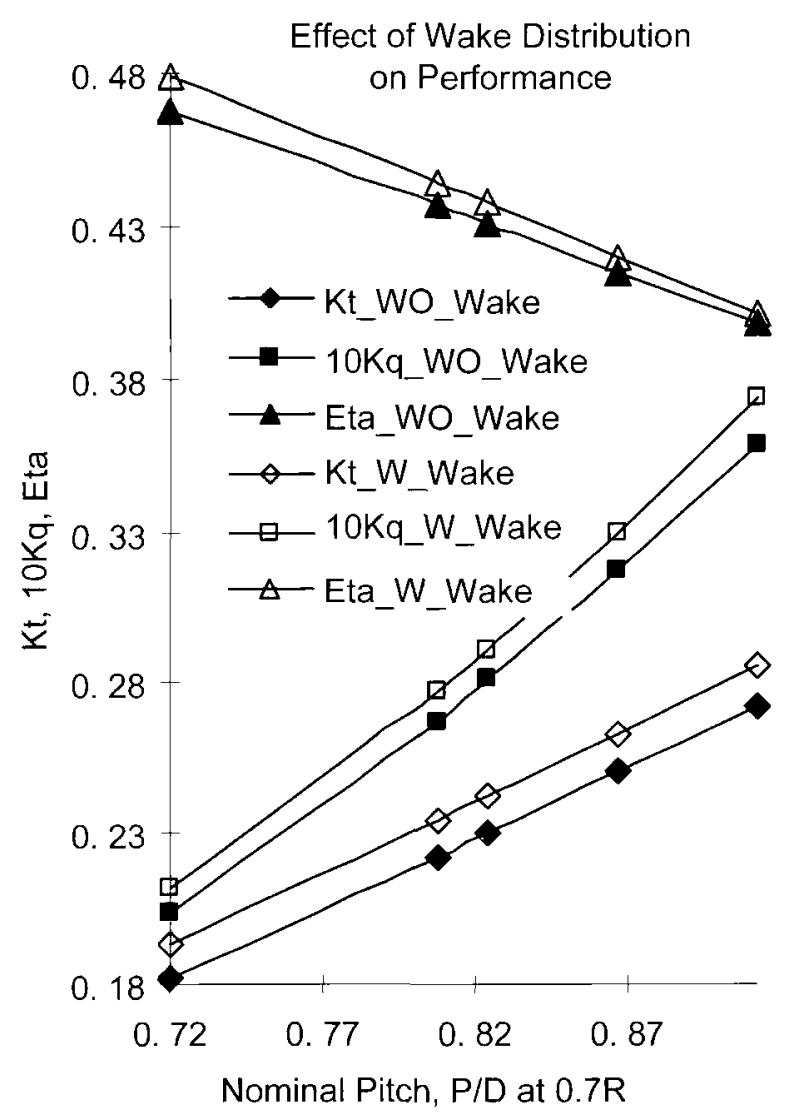

Fig. 20 Performance comparison of the optimized propeller working in the wake of tunnel hull and working in the open water

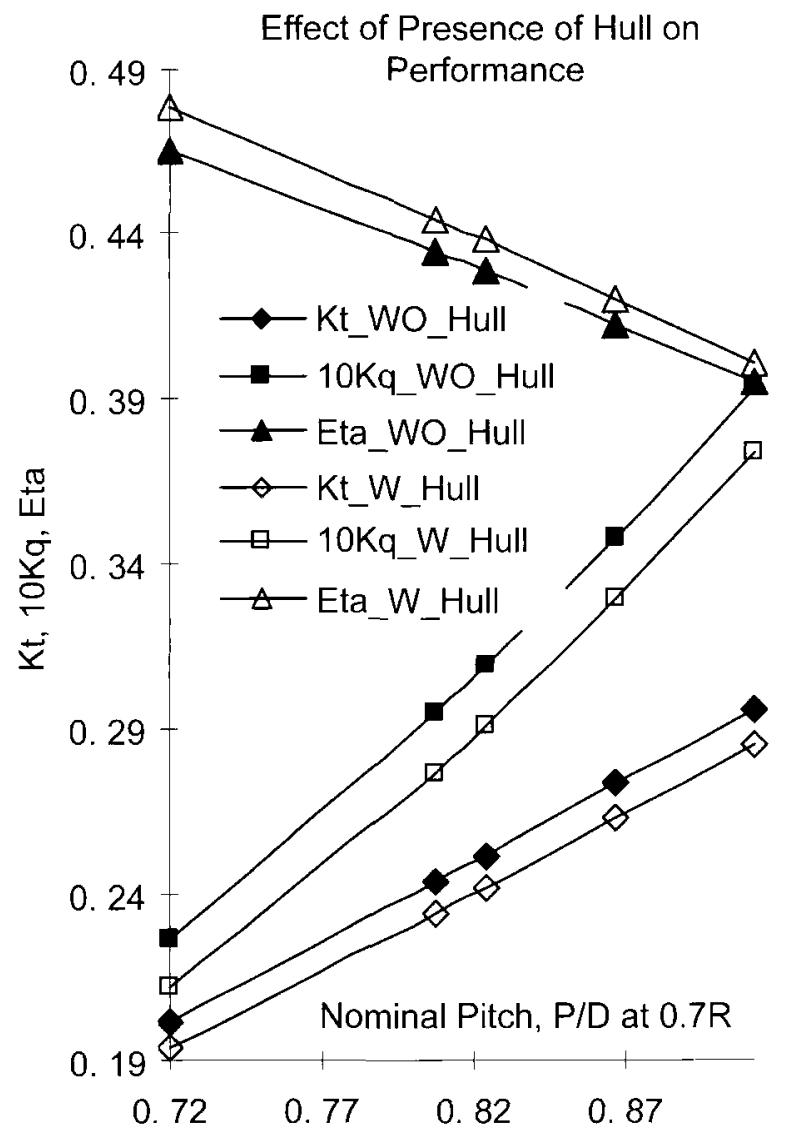

Fig. 21 Comparison of the propeller with and without tunnel gap effect, with a variation of pitch distributions at $J=0.33$ and $n=7.5 \mathrm{rps}$
Propulsive Performance of Design versus Stock Propeller under Hull+Wake+Cavitation Condition

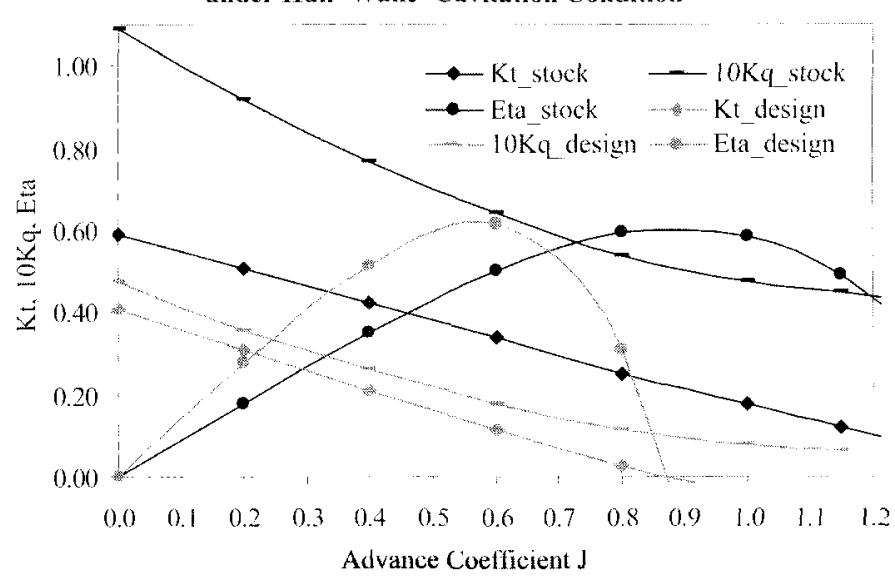

Fig. 22 Comparison of propulsive performance of the design and stock propellers taking into account hull interaction, inflow wake and cavitation correction

attack (more than $20 \mathrm{deg}$ for an infinite aspect ratio steady wing). For the unsteady case and propeller blades treated as semi-infinite wings, separation and stall would be subject to a much lower delay. The largest angle of attack is usually at the blade root sections. To reduce separation and stall that occurs at the root sections, the pitch values at the root were also reduced in design (about $80 \%$ of the pitch at $0.7 R$ ). As the root sections have smaller radii and thus much smaller reference velocities, they have little contribution to total thrust. Therefore, even if there is a minor or moderate separation and stall at root sections, they would not noticeably affect the overall performance of the propeller. However, there has been a remaining issue in panel method: at heavily loaded conditions, as the unsteady pressure difference at the trailing edge of the blade becomes substantially large and the influence matrix becomes ill-conditioned, a plain panel method, on the other hand, usually underpredicts thrust and torque substantially. This means that even though basic panel methods cannot predict separation and stall, they predicted a much smaller thrust and efficiency at heavily loaded condition than in case of separation and stall. PROPELLA was developed to be able to handle heavily loaded condition by using several numerical techniques, including a robust iterative matrix solver to solve for illconditioned matrix, the BICG-STAB method, and a stable and divergent-free iterative numerical Kutta condition process, the Broyden iteration scheme.

- To investigate the effect of the gap and the inflow wake effects, comparisons were made independently. In the design process for the optimum thrust and efficiency, that is, in determining the optimum pitch distribution to maintain the required thrust for the highest possible efficiency, both gap effect and inflow wake were taken into account in all the computations.

\section{Conclusion}

A design and optimization procedure developed and used for a propeller installed on a twin-semitunnel-hull ship navigating in very shallow and icy water under heavy load conditions is presented. This novel and practical design and optimization procedure is a combination of the base propeller determination using classic design method and the detailed optimization using hydrodynamic code. The procedure described here is suitable for both special-purpose propeller 
and conventional propeller design. A panel method code (PROPELLA) was used to vary the pitch values and distributions and take into account the inflow wake distribution, tunnel gap, and cavitation effects. The methodology developed was then applied on a very shallow water semitunnel ship with two propellers navigating in an icy water environment. The optimized propeller was able to numerically achieve a ship speed 0.02 knots higher than the desired speed and 0.06 knots higher than the classic B-series propeller. Further optimization may also be performed by modifying the blade sectional profile and pressure distribution for cavitation, when special performance characteristics are needed. For the ice class, shallow water propeller, the analysis of the effect of inflow wake and tunnel gap on propulsive performance was presented. The results showed that a slight peak torque and thrust increase is seen when a blade is horizontal pointing at the other propeller (half-ship plane), compared with other positions, which means the optimized propeller has a reasonably small shaft force fluctuation. The pressure coefficient at $0.7 R$ was presented at four different circumferential positions over one revolution and showed that the highest negative pressure coincided with the position where the torques and thrusts were at maximum. At that position, a very small cavitation occurred at the leading edge. The inflow wake has a positive effect on the efficiency because of the increase of the thrust more than the increase of the torque. This is mainly caused by the hull wall effect in terms of the tunnel. The presence of the tunnel also showed a similar effect to nozzle on a propeller. With the presence of the hull, the propeller-produced thrust dropped but with a larger decreased torque requirement. This in combination gave an increased efficiency.

\section{Acknowledgments}

The authors thank the National Research Council and Oceanic Consulting Corporation for their support.

\section{References}

BaRanowski, A. 2005 CCGS Eckaloo Results of Model Tests in Shallow Water Hull Model M634-A: Resistance, Self-Propulsion and Wake 3D, Ship Design and Research Centre, Gdansk, Poland, Technical Report No. RH-2005/T-053E.

Bertaglia, G., Lavini, G., and Scarpa, S. 2004 Hull design and optimization with pod propellers with 5 and 6 blades, Proceedings, First International Conference on Technological Advances in Podded Propulsion, University of Newcastle, Newcastle, UK, 39-57.

FSICR 2005 The Structural Design and Engine Output Required of Ships for Navigation in Ice, Finnish-Swedish Ice Class Rules, Finnish Maritime Administration \& Swedish Maritime Administration.

HESS, J. L., AND VALAREzo, W. O. 1985 Calculation of steady flow about propellers by means of surface panel method, Proceedings, Research and Technology Douglas Aircraft Company, Long Beach, CA

Hotaling, J. M., MeEhan, J. M., AND KarafiaTh, M. 2001 Fisheries research vessel hull and propeller design to maximize hydro acoustic survey efficiency, U. S. Papers for 24th UJNR/MFP, Proceedings, 24th Meeting of the Marine Facilities Panel of the United States Japan Cooperative Program in Natural Resources, November 4-10, Honolulu, HI.

JESSUP, S., AND WANG, H. 1997 Propeller design and evaluation for a high speed patrol boat incorporating iterative analysis with panel method, Proceedings, SNAME Propellers and Shafting Symposium.

KERWIN, J. E., AND LEE, C.-S. 1978 Prediction of steady and unsteady marine propeller performance by numerical lifting surface theory, SNAME Transactions, 86, 218-253.

Li, P. 1996 Software Development on Propeller Geometry Input Processing and Panel Method Predictions of Propulsive Performance of the $R$-Class Propeller, MMC Engineering \& Research Report, NL Canada.

LIU, P. 2002 Design and implementation for 3-D unsteady data visualization using object-oriented MFC and OpenGL, JCFD, 11, 3, $335-345$

Lru, P. 2006 The Design of a Podded Propeller Base Model Geometry and Prediction of Its Hydrodynamics, Institute for Ocean Technology, National Research Council Canada (IOT-NRC) Report No. TR-2006-16.

LIU, P., AND BOSE, N. 1998 An unsteady panel method for highly skewed propellers in non-uniform inflow, Proceedings, 22nd ITTC Propulsion Committee Propeller RANS/Panel Method Workshop, 5-6 April, Grenoble, France, 343-349.

LIU, P., BOSE, N., AND Colbourn, B. 2001 Incorporation of a critical pressure scheme into a time-domain panel method for propeller sheet cavitation, Proceedings, International Workshop on Ship Hydrodynamics (IWSH2001), September 22-26, Wuhan, China. 